\title{
Correction to: Bifurcations in a Hamiltonian system with two degrees of freedom associated to the reversible hyperbolic umbilic
}

\author{
Xing Zhou@ • Xuemei Li
}

Published online: 2 August 2021

(C) Springer Nature B.V. 2021

Correction to: Nonlinear Dyn

https://doi.org/10.1007/s11071-021-06629-3

Various typesetting errors have been amended. The original article has been corrected.

Publisher's Note Springer Nature remains neutral with regard to jurisdictional claims in published maps and institutional affiliations.

The online version of the original article can be found under https://doi.org/10.1007/s11071-021-06629-3.

X. Zhou $(\varangle) \cdot$ X. Li

Key Laboratory of High Performance Computing and Stochastic Information Processing, College of Mathematics and Statistics, Hunan Normal University, Changsha, Hunan 410081, China

e-mail: 201710100084@smail.hunnu.edu.cn

X. Li

e-mail: lixuemei_1@sina.com 